\title{
Pet Humanisation: What is it and Does it Influence Purchasing Behaviour?
}

\author{
Sharon L Forbes*, Suzanne Trafford and Madeleine Surie \\ Faculty of Agribusiness \& Commerce, Lincoln University, New Zealand \\ Submission: February 01, 2018; Published: March 22, 2018 \\ *Corresponding author: Sharon L Forbes, Faculty of Agribusiness \& Commerce, Lincoln University, New Zealand, Tel: +64 34230238 ; \\ Email: sharon.forbes@lincoln.ac.nz
}

\begin{abstract}
This opinion paper defines and explores the concept of pet humanisation. In particular, we discuss how the concept has been measured in previous research and argue that an accurate and comprehensive instrument needs to be developed to measure the concept. Until such time, the influence of pet humanisation on the behaviour of pet owners cannot be truly ascertained. We are sceptical that pet humanisation, as it is defined, is in fact driving growth in the pet food market.
\end{abstract}

\section{Introduction}

Pet humanisation has received a lot of attention in the mainstream media and academic literature in recent years. In particular, the relationship between humans and companion animals has been explored by authors in the psychology and sociology disciplines $[1,2]$. It has been variously defined, but in general it can be thought of as a circumstance in which pet owners consider their pet, and their relationship with their pet, as if it was human in nature. Whilst the term 'pet humanisation' has emerged in the academic literature in recent decades, we argue that close, human-like relationships between owners and their pets is in fact a much older phenomenon. Indeed, the phrase "dog is man's best friend" is attributed to Frederick, King of Prussia, in the 1700s. Even earlier in historical terms, Ancient Egyptians are well known for having cherished and indeed idolised their domesticated cats. Dotson and Hyatt [3] cite evidence from historic tomb paintings, artefacts and texts revealing that people kept dogs as beloved pets and members of the family.

In this paper, we review the pet humanisation literature and provide evidence for the existence of this concept. We also raise the question of whether pet humanisation actually matters. In particular, does it have any influence on the behaviour of pet owners, especially in terms of their pet food purchasing decisions and expenditure? We suggest that further research is needed in order to answer this question and that a valid and reliable instrument still needs to be developed to measure the pet humanisation concept. Similarly, other authors suggest that more investigation is needed in order to understand the purchasing pattern of pet owners who demonstrate differing levels of relationships with their pets [4]. Kiesler [5] also notes that the consequences of anthropomorphism in a consumer context are not well understood as yet. In their proposal of an 'animal companion lifecycle and consumer behaviour framework', Aylesworth, Chapman and Dobscha [6] states that research is needed to determine how pet food purchasing decisions are made, and particularly the influence of variables such as price, veterinarians, quality perceptions, and the degree of anthropomorphism may have on the decision makers.

So, is it important to understand the influence of pet humanisation on pet food purchasing behaviour? Given the size and growing value of the pet food market, the answer is yes. In terms of size, data suggests that seventy-three million households in the US have one or more pets, with dogs being found in $39 \%$ of all homes [4]. Recent reports indicate the global pet food sector has grown by more than $\$ 27$ billion over the past five years [7]. Even when national economies are in recession, pet owners continue to spend on their family pets [8-11]. Data suggests that many owners are spending a considerable amount on pet food. Average monthly spending on dog food per dog is highest in Norway at $\$ 53.22$, with Australians spending $\$ 31.44$, an average across the EU of $\$ 14.81$ and a US spend of $\$ 13.89$ [12]. In New Zealand, 64 percent of households own a pet and these owners spend NZ\$1.8 billion per year in caring for their animal companions [13]. Brockman, Taylor and Brockman [14] opine that the increased spending on pets can be attributed to closer emotional ties between owners and their animal companions.

Expenditure on pets goes beyond the essentials such as pet food; today a whole plethora of new pet products and services are available in the marketplace. In many instances, these pet products and services mirror those that are available for humans and thus suggest that humanisation of pets is driving the 
demand. For example, Denniss [9] notes the emergence of pet products such as breath freshening foods, jewellery, float coats, pet cologne and designer name tags. Vanska [15] examined 'babyfied dogs' and described specialty stores in Tokyo catering to pet 'parents' with a range of fashion clothing, prams, diapers, shampoos, jewellery, nail polish, coat dye and foods from sushi to birthday cakes. Companies which have traditionally marketed products to humans are increasingly entering the pet market. For example, brands such as Paul Mitchell, Harley Davidson and Old Navy are offering lines of pet products such as shampoo, fashion and toys [4]. New services such as doggy-daycare centres, dog-walking services, hotels allowing pets, and even frequent flyer programmes for pets, are also increasingly appearing [3]. Other interesting literature has focused on the rising number of custody battles over pets [33] and the growth in demand for pet burial services, cremations and tombs [34].

\section{Pet Humanisation}

Pet humanisation is often used interchangeably with the term anthropomorphism. Anthropomorphism has been defined as the assignment of human-like characteristics, motivations, intentions and emotions to non-human entities [16]. Non-human entities that may be humanised include animals, natural forces, religious deities and even mechanical or electronic devices. For example, Aggarwal and McGill [17] report that consumers may view their car as a loyal companion; some even going so far as to name them. Others report that both products and brands can be humanised by consumers $[18,19]$.

In terms of pets, we can think of humanisation as being the attribution of human thought, feelings, motivations and beliefs to non-human animals [20]. Similarly, Foote [21] describes the concept as the attribution of a full range of human characteristics to animals, including behaviour, thoughts, personality, appearance, mutual understanding and communication. Using a survey of dog owners, Dotson and Hyatt report that anthropomorphism is one of seven dimensions of dog-companionship; they state that in this dimension, owners more often see their dog as a human than an animal, often perceiving the pet to be a child surrogate or a member of their family. Dog owners also reported that they could communicate with their dog much as they could with another human.

Denniss [9] also opines that owners are increasingly treating pets, particularly cats and dogs, as valued family members or as substitute children. This may be linked to the idea that pets can fulfil various roles in an owners' life. For instance, Mosteller [22] state that pets can be viewed as an extension of the self, an extension of family, or as a friend. Foote notes that pets can be assigned the role of surrogate humans, particularly substitute children, siblings, partners or friends, while Gadberry and White [23] argue that pets are often viewed as an intimate family member. Supporting these arguments, Holbrook and Woodside [24] state that many owners regard their pets as surrogate children or substitute grandchildren. It can be observed that in many of these roles, a pet will be humanised or anthropomorphised by its owner.
Various owner behaviours have been found to be indicative of pet humanisation. For example, [25] reported that owners who talk to their pets are treating them as surrogate humans. Other behaviours that are suggestive of pet humanisation include the use of human names for pets and the ascribing of personality traits to them [26], and the use of human terms such as friend, kindred spirit, soulmate, partner or child to describe a relationship to a pet [21]. Owners who mostly keep their pet indoors, who allow them access to all rooms in their home, and who share their bed with their pet are also demonstrating pet humanisation behaviours [27]. Aylesworth, Chapman and Dobscha report that spending on pets in the US increases during holiday periods, suggesting that gift-giving behaviour is no longer limited to only human family members.

\section{The Influence of Pet Humanisation on Purchasing Behaviour}

Whilst pet humanisation has been variously defined and discussed in academic literature, little research has examined the influence of the concept on the purchasing behaviour of owners, particularly with regards to pet food. The following section reviews the literature examining the influence of the pet humanisation concept on pet owner purchasing behaviour.

Firstly, several studies have examined the relationship between pet humanisation and expenditure on veterinarian services. In a US study, Lue, Pantenburg and Crawford used telephone interviews, telephone surveys and online surveys of a large sample of cat and dog owners to identify the bond between an owner and a pet, and the impact of this on the care the pet receives. The authors report that owners with the highest level of involvement with their pet will seek care from veterinarians more frequently, will be more likely to follow advice from veterinarians, and are less sensitive to the cost of veterinarian visits. In another US study, depth interviews of a small sample of veterinarian decision makers revealed that owners who view their pet as a cherished family member make emotional rather than cognitive pet-health decisions; these owners are willing to keep these animals alive regardless of the financial costs [14]. In a loosely related study, Gadberry and White discuss how owners who view their companion animals as beloved family members are driving the growth of pet cremations and cemeteries; there are now more than five hundred pet cemeteries in the US. This type of service provides owners with a way to farewell their pets with love and dignity, as they would do for other family members too.

Secondly, some researchers have reported a link between pet humanisation and the growing expenditure on pet foods and other pet care products. Denniss suggests that Australians are a nation of pet lovers, with $64 \%$ of households containing one or more pets and a total spend of $\$ 1.5$ billion on pet care products in 2003. He asserts that the growth in sales of premium or superpremium pet foods and other pet products is being driven by the humanisation of pets. Owners who view a pet as a cherished family member feel a need to spoil their pet to indicate their love 
and affection. One way to achieve this is through the purchasing and provision of premium pet products. Denniss opines that this overconsumption of pet products is occurring regardless of the financial hardships facing individual consumers. Fleenor [28] reported that the economic downturn had no effect on pet spending. In particular, she suggested that the pet humanisation trend was responsible for the strong growth in the premium pet food market; owners want to pamper their pets and care for their health through products they perceive to be nutritionally superior. In many instances, these premium pet foods are again mirroring what is happening in the human food market; manufacturers are increasingly producing 'natural', 'organic', and 'free from additives' options or products that make health related claims. Indeed it has been stated that the changes being seen in the pet food market are closely reflective of the major trends evident in the human food market [29]. More recently, Ferdman [30-32] suggests that women who are delaying or forgoing motherhood are increasing small dog ownership rates in the US. These owners are increasingly treating these pets as substitutes for human children. He asserts that the growth in sales of premium dog food is being driven by this humanisation trend. However, none of the aforementioned papers have been based on empirical data.

We have found that just two previous studies have empirically examined the owner-pet relationship and pet food purchasing behaviour. In the first of these studies, the primary focus of the Lue, Pantenburg and Crawford research was to understand the impact of the owner-pet bond on the veterinarian care that pets receive; they also questioned their large sample of US cat and dog owners about their pet food choice. In this study, pet humanisation was not specifically measured; rather, the authors used four items to indicate the level of owner-pet bond. These items were: 'would spend any amount necessary to keep pet healthy'; 'considers pet a child'; 'often buys gifts for pet'; and 'misses pet when owner is away from home'. Whilst some of these items might be indicative of pet humanisation, we believe that additional behavioural items would be needed in order to more fully measure the concept of pet humanisation (e.g. 'talk to pet', 'keep pet mostly indoors' and 'allow pet to sleep in owners bed'). Analysis revealed that the feeding of specialty foods was correlated with those who had a strong owner-pet bond; this suggests that pet humanisation might result in the purchasing of more premium or specialty pet foods, but does not fully provide evidence for this relationship.

In the second study, Boya, Dotson and Hyatt identify segments of dog-owner relationships and examine food choice criteria. In this US study, an initial interview of 75 respondents was followed by a survey of 745 dog owners. In their earlier paper, Boya, Dotson and Hyatt documented how they measured eight shopping related behavioural variables and identified three clusters of dog owners from these; 'strongly attached owners', 'moderately attached owners' and 'basic owners'. Price was no issue for owners in the first segment and they are prepared to spend money on their dogs in terms of premium foods and gifts. Those in the second segment indicate a less strong agreement for the items and do not agree that price is no object. Owners in the final segment were found to meet their dog's basic needs. We argue that the measurement of dog attachment using shopping related variables is not equivalent to measuring the pet humanisation concept. The authors subsequently performed factor analysis on twenty-eight items representing various dimensions of the dog-owner relationship and revealed these items loaded on six factors: 'dog-oriented lifestyle', 'anthropomorphism', 'structure and discipline', 'utilityoriented', 'companionship boundaries' and 'appearance'. Seven items were found to load on the anthropomorphism factor and those dog owners in the 'strongly attached' cluster were more likely to attribute human characteristics to their dogs ('basic owners' did not). The authors describe this factor as revealing "the extent to which dog owners attribute human characteristics to their dogs and treat them as members of their family" (pg 139). However, the item 'part of the family' did not in fact load to the anthropomorphism factor, but rather to the dog-oriented lifestyle factor. This creates some confusion over these results. In their later paper [8] documented the measurement of a number of attitudinal items and the subsequent cluster analysis to segment owners into three distinct clusters; 'dog people', 'dog parents' and 'pet owners'. Owners in the first segment are heavily absorbed with their dogs, strongly identify with their dogs, define themselves in terms of their relationship with their dogs, and treat their dogs like people. Those who are dog parents are less likely to define themselves in terms of their dogs, but the regard their dogs as being a part of their family, much like a child would be; the authors suggest that owners in this segment are part of the anthropomorphism trend in the dog market. In the final segment, owners view their dog primarily as a pet and not as a child (NB. this is the smallest of the three segments). The study identified differences across the three segments in terms of the importance they ascribe to various food choice criteria. Dog people score significantly higher than the other two segments in terms of health/nutrition, quality, freshness, taste, and variety in their dog's diet. Dog parents place the most importance on health/nutrition, quality and freshness, but their ratings are significantly lower than those in the dog people segment. The importance of price, ease of preparation, and being on sale criteria were not rated significantly different across the three segments. We would argue that their instrument lacked the behavioural items that would be necessary to comprehensively measure pet humanisation. For example, one of their items is 'I feel like I can communicate with my dogs', but prior literature suggests that those owners who humanise their pet actually do talk to them as they would to another human being. Other behaviour items such as gift giving or sleeping in owners beds are also missing from their instrument.

\section{Conclusion}

As the relationship between an owner and a pet strengthens to one that is more human-like in nature, it would seem likely that they would wish to spoil and reward their pet for their 
unconditional love and companionship. Such behaviour would echo the behaviour of those who are in loving relationships with other humans. Thus it is entirely plausible that pet humanisation could have an influence on the purchasing behaviour of pet owners.

Before the plausibility of any such relationship can be examined, we contend that further work is necessary in order to develop an instrument to accurately and comprehensively measure the concept of pet humanisation. This will not be an easy task. For example, the literature suggests that talking to a pet is behaviour characteristic of pet humanisation. As pet owners ourselves, and as researchers who have interviewed pet owners, we suspect that most if not all pet owners talk to their companion animals. If we think about this item alone, the differences between those who have humanised their pet and those who view it as an animal are possibly quite small. Thus the instrument will need to be finely tuned in order to differentiate between those owners who have frequent and lengthy (but one-sided) conversations with their pets and those who speak less frequently and more briefly to their pets. With regard to this single item, perhaps that is the subtle difference between owners; one group is talking with their pets as if it is a two-way communication and the other group is talking to them. We believe that the final developed instrument might consist of multiple items and that no previous research has, to date, used an instrument that fully measures pet humanisation and thus differentiate between owners. For example, the literature mentions the development of a wide range of new pet products and services that mirror human products. We suggest that owners who view their pets as animals would be unlikely to purchase human-like products such as jewellery, cologne, prams, nail polish, or fashion clothing for their pets. An item or items relating to the purchase of the above mentioned products Items would thus differentiate between owners who see their animal as a human from those who have not humanised their pets. However, those who put jewellery, cologne or nail polish on their pet may not have humanised them at all; they may instead be viewing their animal companion as a fashion accessory or as a trophy. This just goes to demonstrate that the use of a single item scale will not be robust enough to fully measure the pet humanisation concept.

Once a valid and reliable instrument has been developed and tested, researchers can ascertain if pet humanisation has any influence on the purchasing behaviour of owners. Whilst we believe that it is likely that owners who humanise their pets are more likely to purchase products that mirror human ones (as listed above), we are sceptical that humanisation will influence pet food purchasing behaviour. There are a number of reasons for our scepticism. Firstly, we think that an owner's personal lifestyle-related consumption choices will have a significant influence on how they purchase for their pet, regardless of the degree to which they have humanised the animal. For example, someone who passionately follows an organic diet themselves will be much more likely to purchase organic pet food. Similarly, the pet food products claiming additional health benefits or promoting natural ingredients are probably more appealing to owners who are health-conscious about their own diets and eating natural products. Secondly, we think that specific product attributes will have a more significant impact on the owner's choice of pet food than will pet humanisation levels. Despite its questionable nutritional value, biscuits or kibble remain the most heavily purchased type of food for cats and dogs. In our interviews we have listened to owners talk about the messiness of handling many of the alternative products, such as cans or pouches of wet food; they also mention the undesirable aroma associated with these products. If an owner feels nauseated when handling some types of pet foods, then they will not purchase them no matter how much they have humanised their pet. Another important attribute is price. Despite the growth in the premium pet food market and claims that it is recession-proof, we do not believe that any owner would prioritise spending on pet food above the purchasing of food for their human family members. It would be logical that in difficult financial times, decision makers would seek to cut down on spending across the board and this would include pet food, even for humanised pets. Convenience also has a part to play. Many of the premium or super-premium brands are not readily available in all supermarket chains. Consumers today are busy people and we think they will be putting pet food into their shopping trolleys at the same time as they stock up on food for other household members; even if they have humanised their pet, are they going to go out of their way to visit a veterinarian clinic or pet-store to purchase a more specialist product? Finally, we would question whether pet humanisation would influence the purchasing of pet food as, by its very nature, such behaviour would surely lead owners to share their human food with their animal. Information from our interviews with pet owners would suggest there may be some truth to this idea; several owners who were strongly attached to their cats or dogs spoke about feeding their animals with leftovers from their own table. Food that was mentioned included vegetables, pasta, rice, cooked chicken and raw steak. If you chose to humanise your pet, would you then feed it pet food that mostly looks and smells rather unappealing? We suspect that owners who most strongly humanise their pets are not frequent purchasers of commercially prepared pet food products.

This paper has defined the concept of pet humanisation and provided some evidence of its existence. Once a valid and reliable instrument is developed to measure concept, we believe that owners will be able to be described as sitting somewhere along a continuum of low to high levels of pet humanisation. It is possible, indeed probable, that owners at the high end of the continuum will display higher purchasing of some pet care products or services. For example, we would assert that this group would use veterinarian services more often and would be more likely to purchase products that mirror human ones such as pet jewellery or colognes. But the question of whether pet humanisation has any influence on the pet food purchasing decisions of owners has not been fully answered at this point in time; further research is needed to advance current knowledge. 


\section{References}

1. Belk R (1988) Possessions and the extended self. Journal of Consumer Research 15: 139-168.

2. Hirschman EC (1994) Consumers and their animal companions. Journal of Consumer Research 20(4): 616-632.

3. Dotson MJ,Hyatt EM (2008) Understanding dog-human companionship. Journal of Business Research 61: 457-466.

4. Boya UO, Doston MJ, Hyatt EM (2012) Dimensions of the doghuman relationship: A segmentation approach. Journal of Targeting, Measurement and Analysis for Marketing 20(2): 133-143.

5. Kiesler T (2006) Anthropomorphism and consumer behaviour. Advances in Consumer Research 33: 149.

6. Aylesworth A, Chapman K, Dobscha S (1999) Animal companions and marketing: Dogs are more than just a cell in the Bcg Matrix! Advances in Consumer Research, 26: 385-391.

7. Sherson V (2017) A dog's dinner: The booming business in pets. North \& South.

8. Boya UO, Doston MJ, Hyatt EM (2015) A comparison of dog food choice criteria across dog owner segments: An exploratory study. International Journal of Consumer Studies 39: 74-82.

9. Denniss R (2004) Overconsumption of pet food in Australia. The Australia Institute: Manuka, ACT.

10. Pathfinder (2010) Pathfinder Report: Global Pet Food Trends. Agriculture and Agri-Food Canada.

11. PMMI (2013) Pet food market assessment: Market assessment that explores the trends, issues and expectations in the pet food industry.

12. Bradley T, King R (2012) The dog economy is global - but what is the world's true canine capital? The Atlantic.

13. Shaw A (2018) What's a pet worth? \$1.8b, say Kiwi animal lovers.

14. Brockman BK, Taylor VA, Brockman CM (2008) The price of unconditional love: Consumer decision making for high-dollar veterinary care. Journal of Business Research 61: 397-405.

15. Vanska A (2014) New kids on the mall: Babyfied dogs as fashionable co-consumers. Young Consumers 15(3): 263-272.

16. Epley N, Waytz A, Cacioppo JT (2007) On seeing human: A three-factor theory of anthropomorphism. Psychological Review 114(4):864-886.

17. Aggarwal PJ, McGill AL (2007) as a basis Is that car smiling at me? Schema congruity for evaluating anthropomorphized products. Journal of Consumer Research 34: 468-479.

18. Biel AL (2000) Converting image into equity. Brand Equity and Advertising: Advertising's Role in Building Strong Brands. Aaker DA \& Biel AL (Eds.), Hillsdale, NJ: Erlbaum.
19. Fournier S (1998) Consumers and their brands: Developing relationship theory in consumer research. Journal of Consumer Research 24: 343373.

20. Serpell JA (2003) Anthropomorphism and anthropomorphic selection - beyond the cute response. Society \& Animals 11(1): 83-100.

21. Foote D (2006) The human animal bond. In: Proceedings of the Australian Veterinary Association Conference-Practice management stream.

22. Mosteller J (2008) Animal-companion extremes and underlying consumer themes. Journal of Business Research 61: 512-521.

23. Gadberry JH, White R (2013) Companion animals: A social history of anthropomorphism. International Journal of Social Science Research 2: 61 .

24. Holbrook MB, Woodside AG (2007) Animal companions, consumption experiences, and the marketing of pets: Transcending boundaries in the animal-human distinction. Journal of Business Research 61(5): 377-381.

25. Sanders CR (1990) The animal other self: Self-definition, social identify and companion animals. Advanced Consumer Research 17(1): 662668.

26. Chartrand TL, Fitzsimons GM, Fitzsimons GJ (2008) Automatic effects of anthropomorphized objects on behaviour. Social Cognition 26(2): 198-209.

27. Lue TW, Pantenburg DP, Crawford PM (2008) Impact of the ownerpet and client-veterinarian bond on the care that pets receive. JAVMA 232(4): 531-540.

28. Fleenor DG (2009) Only the best for Fido and Fluffy. Progressive Grocer 88(4): $12-14$

29. Schaffer M (2009) One nation under dog: Adventures in the new world of Prozac-popping puppies, dog-park politics, and organic pet food. Macmillan: New York, USA.

30. Ferdman RA (2014) Americans are having dogs instead of babies.

31. Furore K (2014) All in the family. Progressive Grocer.

32. Coriolis (2014) Investment opportunities in the New Zealand pet food industry. Report produced as part of the Food and Beverage Information Project.

33. Wharton, T. C. (2007). Fighting Like Cats and Dogs: The Rising Number of Custody Battles Over the Family Pet. JL \& Fam. Stud., 10, 433.

34. Chur-Hansen, A. (2011). Cremation services upon the death of a companion animal: Views of service providers and service users. Society \& Animals, 19(3), 248-260.

Your next submission with Juniper Publishers
will reach you the below assets
- Quality Editorial service
- Swift Peer Review
- Reprints availability
- E-prints Service
- Manuscript Podcast for convenient understanding
- Global attainment for your research
- Manuscript accessibility in different formats
( Pdf, E-pub, Full Text, Audio)
- Unceasing customer service
Track the below URL for one-step submission
https://juniperpublishers.com/online-submission.php

